\title{
Late cutaneous metastases to the face from malignant pleural mesothelioma: A case report and review of the literature Alaaeldeen M Elbahaie*1, Dia E Kamel ${ }^{2}$, Julia Lawrence ${ }^{3}$ and Neville G Davidson ${ }^{1}$
}

\author{
Address: ${ }^{1}$ Clinical Oncology Department, Mid Essex Hospital Services NHS Trust, Broomfield Hospital, Court Road, Chelmsford, CM1 7ET, UK, \\ ${ }^{2}$ Histopathology Department, Mid Essex Hospital Services NHS Trust, Broomfield Hospital, Court Road, Chelmsford, CM1 7ET, UK and \\ ${ }^{3}$ Radiotherapy Department, Colchester Hospital University NHS Foundation Trust, Essex County Hospital, Lexden Road, Colchester, CO3 3NB, \\ UK \\ Email: Alaaeldeen M Elbahaie* - aelbahaie@nhs.net; Dia E Kamel - dia.kamel@meht.nhs.uk; \\ Julia Lawrence - julia.lawrence@colchesterhospital.nhs.uk; Neville G Davidson - neville.davidson@meht.nhs.uk \\ * Corresponding author
}

Published: 9 November 2009

World Journal of Surgical Oncology 2009, 7:84 doi:10.1/86/1477-78/9-7-84

Received: 27 August 2009

Accepted: 9 November 2009

This article is available from: http://www.wjso.com/content/7/I/84

(c) 2009 Elbahaie et al; licensee BioMed Central Ltd.

This is an Open Access article distributed under the terms of the Creative Commons Attribution License (http://creativecommons.org/licenses/by/2.0), which permits unrestricted use, distribution, and reproduction in any medium, provided the original work is properly cited.

\begin{abstract}
Background: Malignant Mesothelioma is a rare primary neoplasm affecting the serosal membranes. During its relative short course, this malignant neoplasm can give local and, rarely, distant haematogenous metastases in different organs. The reported metastatic sites include liver, lung, heart, brain, thyroid, adrenals, kidneys, pancreas, bone, soft tissue, skin and lymph nodes.

Case Presentation: We report a sixty one year-old man with a history of malignant pleural epithelioid mesothelioma treated with six cycles of Pemetrexed and Carboplatin completed 03/I I/ 04 followed by radiotherapy to the drain site $250 \mathrm{Kv} / \mathrm{TD} 20 \mathrm{~Gy} / 5 \mathrm{~F}$ completed I3/I2/2004. Then he developed multiple facial skin lesions 4 years later. These lesions were proved to be metastatic malignant sarcomatoid mesothelioma.
\end{abstract}

Conclusion: Mesothelioma metastases should be suspected in any known Mesothelioma patient with newly developed skin lesion.

\section{Background}

Malignant Mesothelioma is a rare primary neoplasm affecting the serosal membranes. During its relative short course, this malignant neoplasm can give local and, rarely, distant haematogenous metastases in different organs. The reported metastatic sites include liver, lung, heart, brain, thyroid, adrenals, kidneys, pancreas, bone, soft tissue, skin and lymph nodes. The increased incidence of malignant mesothelioma and the improvement of survival rates due to the newly introduced chemotherapeutic agents bring to light the importance of studying its amended natural history.

\section{Case Presentation}

A 61 year-old white man with known history of pleural mesothelioma on regular follow up was found to develop multiple facial skin lesions with no clinical evidence of local recurrence 4 years after the primary diagnosis.

On March 2004, this non-smoker, semi-retired boat builder with significant asbestos exposure history, presented with 4 months history of progressive shortness of breath. The inhalers had not helped and this seemed to be clearly a different problem to his original asthma. He also complained of some right chest pain, easy fatigue, dry 
cough and weight loss. On examination, there were only signs of pleural effusion. The chest X-rays showed increasing right pleural effusion and CT chest showed a large right simple pleural effusion with no pleural thickening or masses. He was admitted and the effusion drained. The cytology of the effusion was highly suggestive of mesothelioma, but pleural biopsy was insufficient. Few weeks later, the pleural effusion recurred and an US guided biopsy on 08/06/04 showed features consistent with a malignant Mesothelioma, epithelioid type (Fig. 1). The biopsy contains some skeletal muscle and some pleura with a thick layer of malignant epithelioid cells which are positive for mesothelial markers CK5/6 and Calretinin and negative for lung cancer markers TTF-1 and CEA.

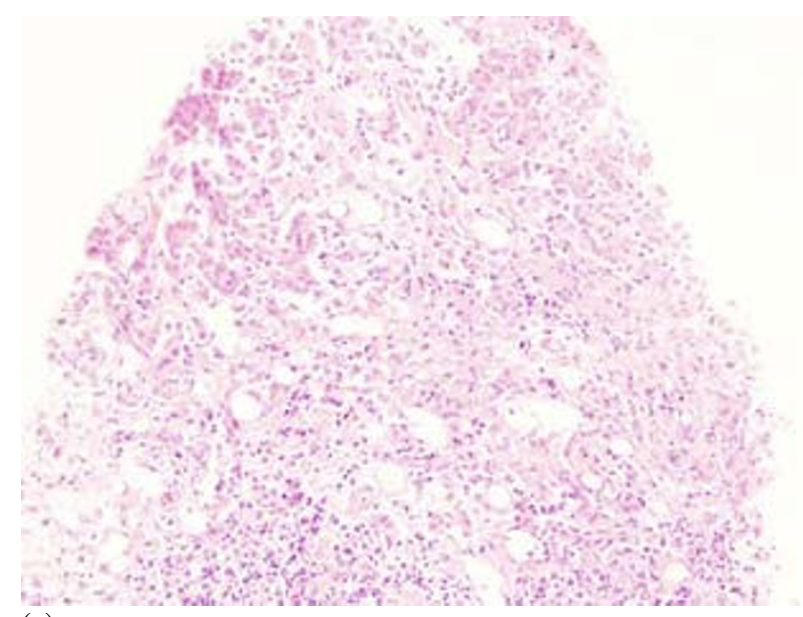

(a)

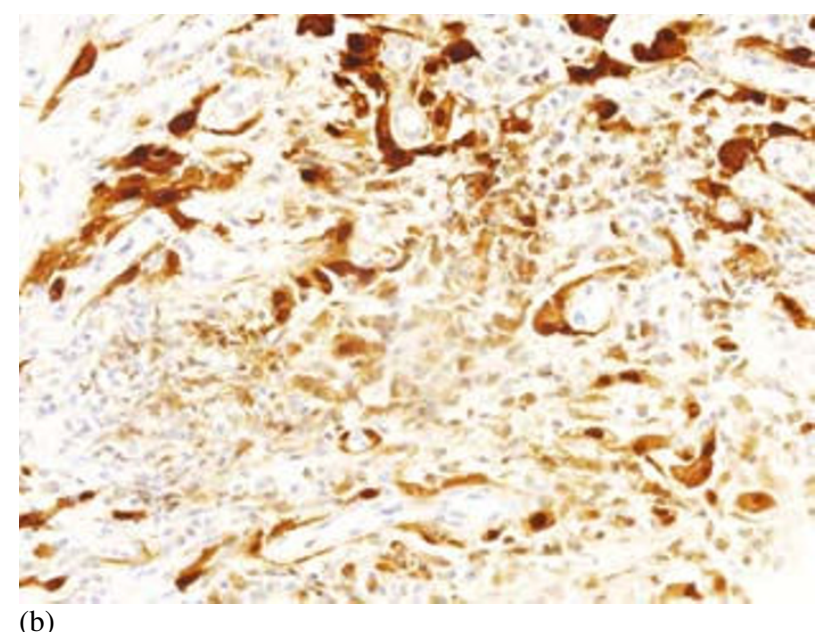

(b)

Figure I

Original pleural biopsy on June 2004, showing infiltration by epithelioid tumour cells (a), which are positive with immunohistochemical staining for Calretinin (b), consistent with epithelioid mesothelioma.
The patient took part on the ALIMTA trial, he received 6 cycles of Pemetrexed $500 \mathrm{mg} / \mathrm{m}^{2}+$ Carboplatin AUC 5 day 1 every 3 weeks; the last cycle date was $03 / 11 / 04$. This was followed by radiotherapy to the drain site "250 Kv/TD20 Gy/5F" completed 13/12/2004.

Then, the patient underwent close follow up and he remained well and asymptomatic with no clinical or radiological evidence of disease recurrence until the end of December 2007, when he noticed small subcutaneous lesion on his right check and some nasal symptoms. Few weeks later, he developed fever $38^{\circ} \mathrm{C}$ with dry cough and the cheek lesion increased in size. CT scan on 17/03/2008 recorded several sites of disease; notably in the right hemithorax and right para-renal space consistent with recurrence of the Mesothelioma. Clinical Examination of the face revealed 3 skin lesions: right cheek $24 \times 24 \mathrm{~mm}$
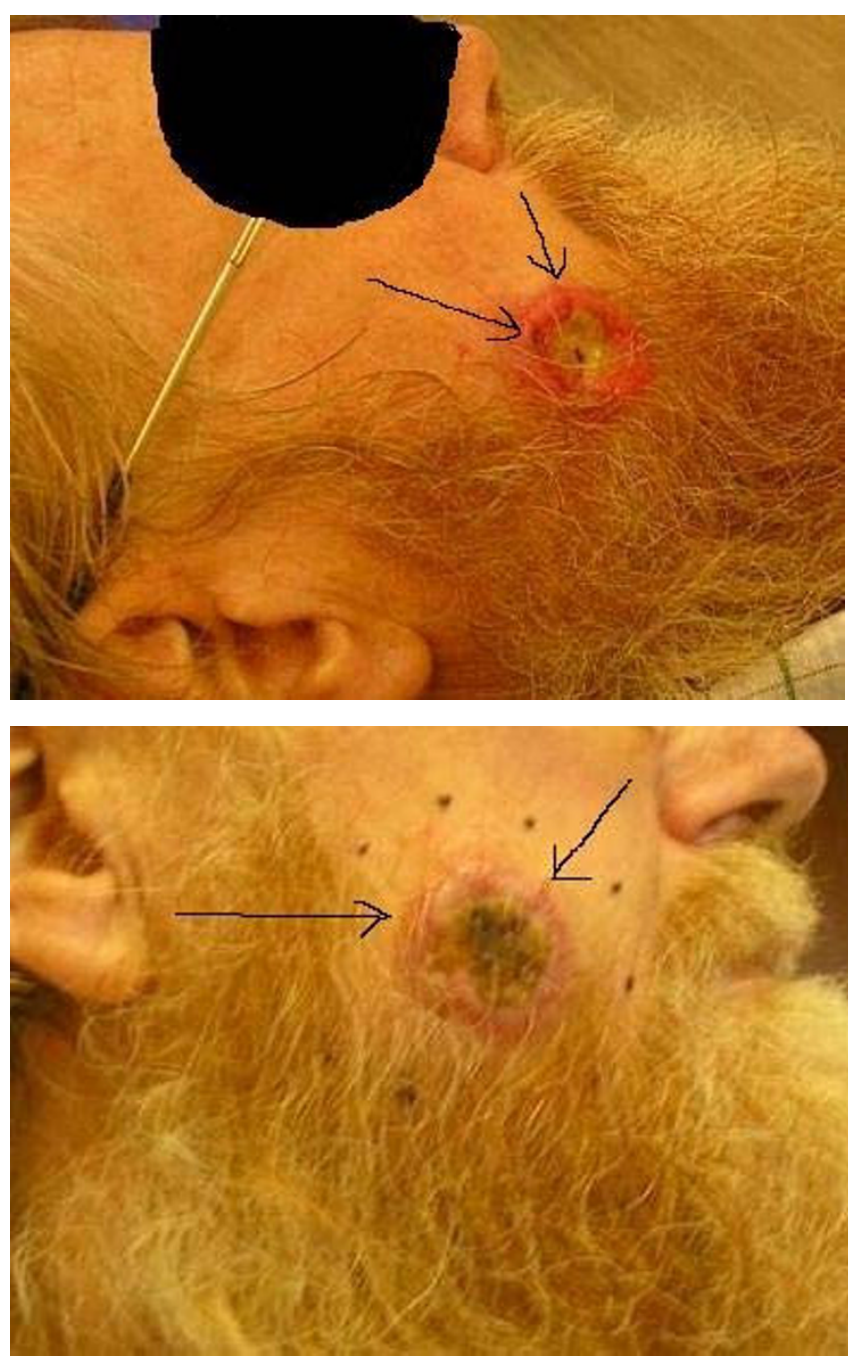

Figure 2

Photos of skin lesion in the right cheek. 
annular raised red area with eroded central area (Fig. 2), a small erythematous plaque posterior to the right ear and a $1 \mathrm{~cm}$ very firm subcutaneous lesion on the frontal area.

CT guided core biopsy from the right posterior basal pleural mass showed a thick layer of malignant epithelioid cells. A panel of immunohistochemical markers were performed and these malignant cells are positive for mesothelial markers CK5/6 and Calretinin and negative for lung cancer markers TTF-1 and CEA. Overall, these features are consistent with a malignant Mesothelioma, Epithelioid type.

The three skin lesions were biopsied. The microscopic examination showed sarcomatous atypical spindle cell proliferation within the dermis extending into the subcutaneous adipose tissue (Fig. 3). Mitotic figures including atypical forms are noted. The architecture of the tumour is partly storiform. Immunohistochemistry showed positivity with Vimentin, CAM 5.2 and CD10 and focally with SMA and Calretinin. The histopathological diagnosis was in keeping with Metastatic Mesothelioma of sarcomatous type.

\section{Discussion}

Malignant Mesothelioma is a rare primary neoplasm affecting the serosal membranes with a relative increase of its incidence rate during the last decades [1]. Most cases of mesotheliomas are related to asbestos exposure [2]. Its incidence has been rising steadily over the past few decades [1]. Approximately 1000 people die of mesothelioma each year in the $\mathrm{UK}$, and it is predicted to rise to 3000 by the year 2020 [3].

Histologically, Mesothelioma is divided into epithelial, sarcomatous and mixed or biphasic subtypes. In several series epithelial type has a significantly improved prognosis compared to sarcomatous variant [4]. The primary diagnosis of our patient was epithelioid type; then the local recurrence was also epithelioid, while the skin metastases are of sarcomatous type; which may be explained by the heterogeneous nature of the disease or the known fact that malignant cells may loose some of there differentiation when metastasis.

Systemic therapy is the only treatment option for the majority of mesothelioma patients. For many years, chemotherapy had a minimal impact on the natural history of this cancer. Countless drugs were evaluated, most of which achieved response rates below 20\% and median survival of $<1$ year [5]. In recent years, there has been a surge of optimism regarding systemic treatment of this disease. Several cytotoxic agents have been shown to generate reproducible responses, improve quality of life, or prolong survival in mesothelioma. Drugs with single- agent activity include pemetrexed, raltitrexed, vinorelbine, and vinflunine [5]. The combination of pemetrexed plus cisplatin is considered the benchmark front-line regimen for this disease, based on a phase III trial in 456 patients that yielded a response rate of $41 \%$ and a median survival of 12.1 months compared to 9.3 months for single agent cisplatin [6]. A recent large International Expanded Access Program confirmed the activity of pemetrexed plus cisplatin and pemetrexed plus carboplatin in chemonaive patients with Malignant Pleural Mesothelioma, demonstrating clinically similar time to progressive disease and 1-year survival rates [7]. Our patient received 6 cycles of Pemetrexed $500 \mathrm{mg} / \mathrm{m}^{2}+$ Carboplatin AUC 5 day 1 every 21 days, completed 03/11/04 with >37 months disease free survival. This long disease free survival in mesothelioma patients is rare; however this may be explained by the small disease burden on primary presentation and/or treatment received.

During its relative short course, this malignant neoplasm, independently of the therapy, can give local or distant haematogenous metastases in different organs. The reported metastatic sites include liver, lung, heart, brain, thyroid, adrenals, kidneys, pancreas, bone, soft tissue, skin and lymph nodes [8,9].

Only small number of cases of subcutaneous metastases of malignant Mesothelioma has been reported. However, the majority of the reported cases were considered as local invasion of the disease. To our knowledge, in English language published articles, there are only 10 reported cases of pleural Mesothelioma with distant subcutaneous metastases [8,10-17]; seven of them had metastases to the face and/or scalp. So, our case is the $11^{\text {th }}$ reported pleural Mesothelioma case with a distant subcutaneous metastasis and it is the $8^{\text {th }}$ case with face and/or scalp subcutaneous metastases $[8,10-14]$.

\section{Conclusion}

With the increased incidence of malignant Mesothelioma and the improvement of survival rates due to the newly introduced chemotherapeutic agents, the number of recorded distant skin metastases is likely to increase. Metastatic disease from mesothelioma should be suspected in any known mesothelioma patient who develops a new malignant skin lesion. 


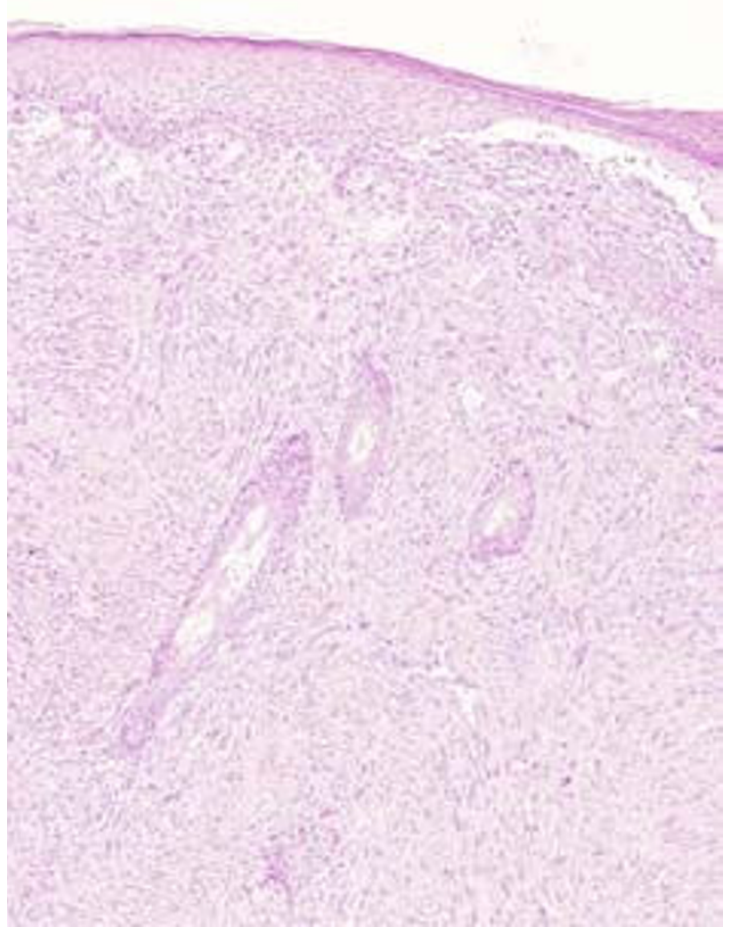

(a)

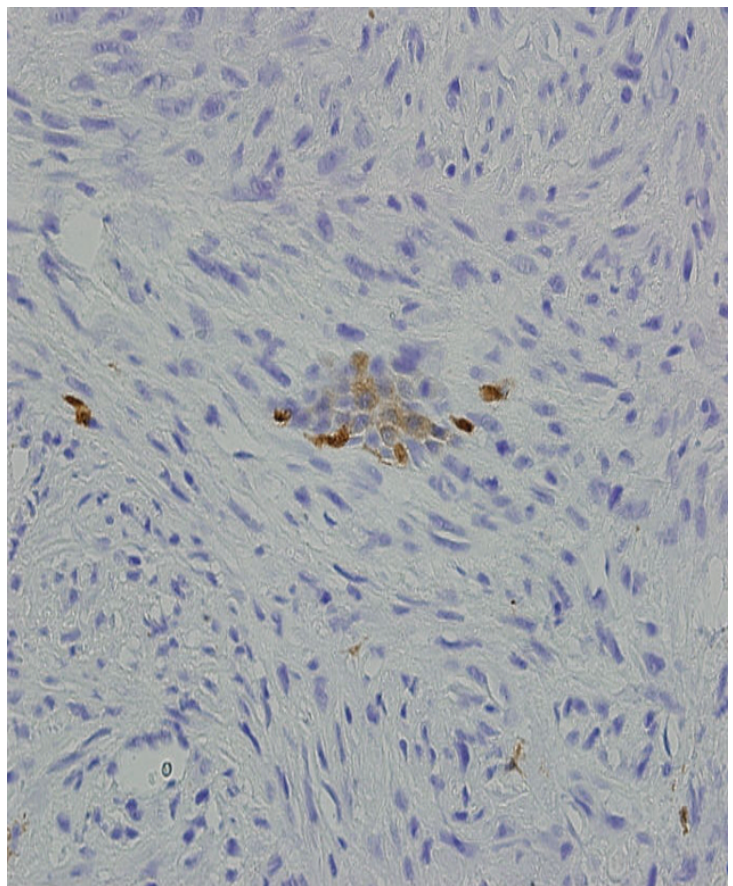

(c)

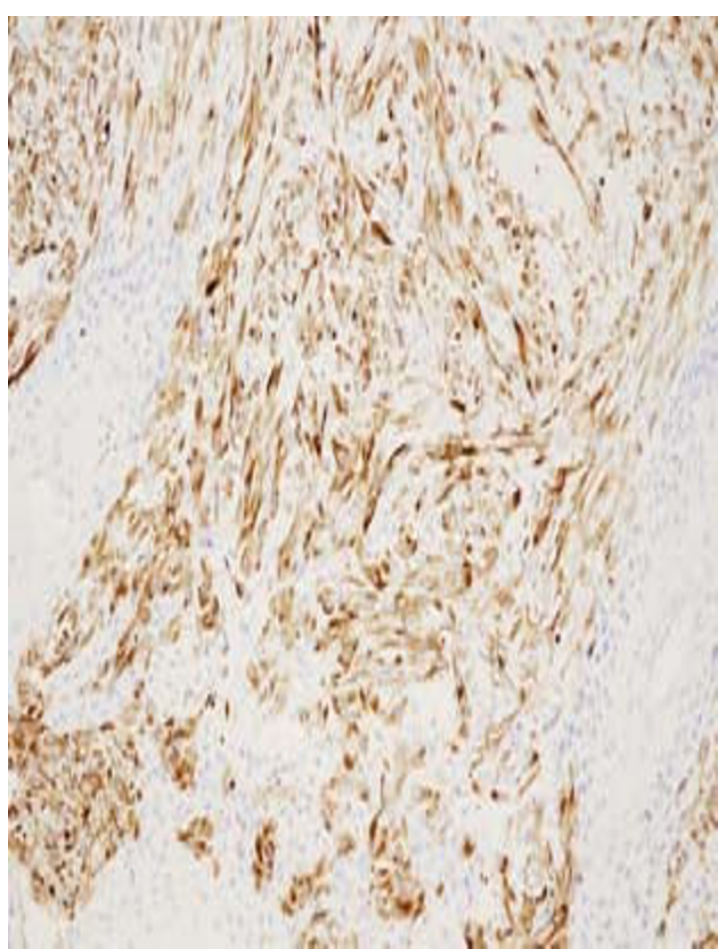

(b)

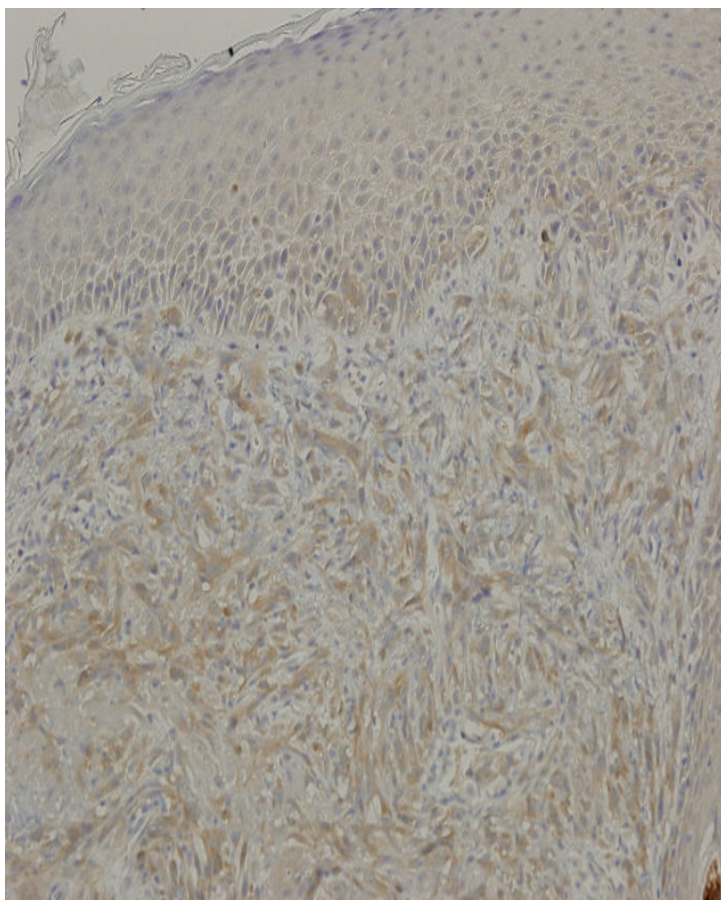

(d)

Figure 3

Skin biopsy on May 2008 showing dermal infiltration by a spindle cell tumour (a), which was positive with cytokeratin CAM5.2 immunohistochemical staining (b), and focally positive with Calretinin (c) and mesothelin (d) consistent with sarcomatoid mesothelioma. 


\section{Competing interests}

The authors declare that they have no competing interests.

\section{Authors' contributions}

$\mathrm{AE}$ is the main author; he did a major part in the clinical work, all the literature review, all the editing work and publication submission. ND is the head of the department who supervised all the steps of the work and his invaluable advices were essential in finalizing the article. DK did the histopathological work. JL shared in the clinical work.

\section{Consent statement}

Written informed consent was obtained from the patient's next of kin (his widow; as the patient is deceased) for publication of this case report and accompanying images. A copy of the written consent is available for review by the Editor-in-Chief of this journal.

\section{References}

I. Antman K: Natural history and epidemiology of malignant mesothelioma. Chest 1993, I 03(Suppl):373-376.

2. Raptopoulos V: Peritoneal mesothelioma. Crit Rev Diagn Imaging 1985, 24:293.

3. Attanoos RL, Gibbs AR: Pathology of malignant mesothelioma. Histopathology 1997, 30:403-4I8.

4. Fusco V, Ardizzoni A, Merlo F, Cinquegrana A, Faravelli B, De Palma M, Chessa L, Nicolò G, Serra M, Capaccio A, et al.: Malignant pleural mesothelioma. Multivariate analysis of prognostic factors on I I 3 patients. Anticancer Research 1993, I 3:683-689.

5. Kindler HL: Systemic Treatments for Mesothelioma: Standard and Novel. Curr Treat Options Oncol 2008.

6. Vogelzang NJ, Rusthoven J, Symanowski J, Denham C, Kaukel E, Ruffie P, Gatzemeier U, Boyer M, Emri S, Manegold C, Niyikiza C, Paoletti P: Phase III study of pemetrexed in combination with cisplatin versus cisplatin alone in patients with malignant pleural mesothelioma. J Clin Oncol 2003, 2 I ( I 4):2636-2644.

7. Santoro A, O'Brien ME, Stahel RA, Nackaerts K, Baas P, Karthaus M, Eberhardt W, Paz-Ares L, Sundstrom S, Liu Y, Ripoche V, Blatter J, Visseren-Grul CM, Manegold C: Pemetrexed plus cisplatin or pemetrexed plus carboplatin for chemonaïve patients with malignant pleural mesothelioma: results of the International Expanded Access Program. J Thorac Oncol 2008, 3(7):756-63.

8. Edstrom L, Dawson P, Kohler J, DeMester T: Malignant mesothelioma: A metastasis to the face. J Surg Oncol 1980, I4:25 I-254.

9. Walters K, Martinez A: Malignant fibrous Mesothelioma metastatic to brain and liver. Acta Neuropathol 1975, 33:173-I77.

10. Beer TW, Heenan PJ: Malignant mesothelioma presenting as a lip tumor: report of two cases with one unrecognized by 166 pathologists. Am J Dermatopathol 2007, 29(4):388-9l.

I I. Kanbay A, Oguzulgen KI, Ozturk C, Memis L, Demircan S, Kurkcuoglu C. Akyurek N, Kurul C: Malignant pleural mesothelioma with scalp, cerebellar, and finger metastases: a rare case. South Med J 2007, I 00(I):63-5.

12. Cassarino DS, Xue W, Shannon KJ: Widespread cutaneous and perioral metastases of mesothelioma. J Cutan Pathol 2003, 30:582-585

13. Müller C, Reichrath J, Tilgen W: Disseminated cutaneous metastasis of a biphasic pleural mesothelioma. J Eur Acad Dermatol Venereol 2008.

14. Dutt PL, Baxter JW, O'Malley FP, Glick AD, Page DLI: Distant cutaneous metastasis of pleural malignant mesothelioma. J Cutan Pathol 1992, 19:490-495.

15. Prieto VG, Kenet BJ, Varghese M: Malignant mesothelioma metastatic to the skin, presenting as inflammatory carcinoma. Am J Dermatopathol 1997, 19:261-265.
16. Patel T, Bansal R, Trivedi P, Modi L, Shah MJ: Subcutaneous metastases of sarcomatoid mesothelioma with its differential diagnosis on fine needle aspiration--a case report. Indian J Pathol Microbiol 2005, 48(4):482-4.

17. Maiorana A, Giusti F, Cesinaro AM, Conti A, Rossi G: Cutaneous metastases as the first manifestation of pleural malignant mesothelioma. J Am Acad Dermatol 2006, 54:363-365.
Publish with Bio Med Central and every scientist can read your work free of charge

"BioMed Central will be the most significant development for disseminating the results of biomedical research in our lifetime. "

Sir Paul Nurse, Cancer Research UK

Your research papers will be:

- available free of charge to the entire biomedical community

- peer reviewed and published immediately upon acceptance

- cited in PubMed and archived on PubMed Central

- yours - you keep the copyright 